\title{
Synthesis and Properties of Novel Polyarylates and Poly(ether ether ketone)s Derived from 2,7-Triptycenediol
}

\author{
Fumihiko Akutsu, ${ }^{\dagger}$ Mari InOKI, Masayuki Kondo, Tomokazu InAGawa, \\ Kazuhiro KaYaKi, and Yoshio KaSASHIMa \\ Department of Applied Chemistry, Faculty of Engineering, Chiba University, \\ Yayoi-cho 1-33, Inage-ku, Chiba 263, Japan
}

(Received June 4, 1997)

\begin{abstract}
Novel polyarylates are obtained by interfacial polycondensations of 9,10-dihydro-9,10- $o$-benzenoanthracene1,5-diol (2,7-triptycenediol; TRIDO) with aromatic diacyl chlorides using benzyltriethylammonium chloride as a phase transfer catalyst. Inherent viscosity ranged from 0.29 to $0.51 \mathrm{dlg}^{-1}$. The glass transition temperatures $\left(T_{\mathrm{g}} \mathrm{s}\right)$ were $243-249^{\circ} \mathrm{C}$, and temperatures at $5 \%$ weight loss $\left(T_{\mathrm{d}} \mathrm{s}\right)$ were above $488^{\circ} \mathrm{C}$. These polyarylates were amorphous. The polyarylate derived from TRIDO and isophthaloyl dichloride showed good solubility in several organic solvents. Novel poly(ether ether ketone)s are prepared by nucleophilic displacement reaction of TRIDO with activated aromatic difluorides, such as $4,4^{\prime}$-difluorobenzophenone (DFBP) and 1,4-bis(4-fluorobenzoyl)benzene (BFBB), using potassium carbonate and toluene. Inherent viscosity ranged between $0.30-0.47 \mathrm{dl} \mathrm{g}^{-1}$. $T_{\mathrm{g}} \mathrm{s}$ were about $230^{\circ} \mathrm{C}$, and $T_{\mathrm{d}} \mathrm{s}$ from 544 to $568^{\circ} \mathrm{C}$. The poly(ether ether ketone) derived from TRIDO and DFBP (2c) possessed high solubility, and that from TRIDO and BFBB (2d) had poor solubility. X-Ray diffraction patterns suggested that $\mathbf{2 c}$ was amorphous and $\mathbf{2 d}$ was semi-crystalline. $2 \mathbf{d}$ melting point was $301^{\circ} \mathrm{C}$. A characteristic semi-crystalline nature was found only in poly(ether ether ketone) $\mathbf{2 d}$ even though aromatic polyamides, polyimides, and polyarylates containing 2,7-triptycenediyl structure were all amorphous.

KEY WORDS Polyarylates / 2,7-Triptycenediol / Poly(ether ether ketone)s / Solubility / Thermal

Properties /
\end{abstract}

Polyarylates and poly(ether ether ketone)s show high thermal and hydrolytic stability, good mechanical properties, and insolubility in organic solvents, and thus are widely used in various fields as coatings, adhesives, composites, molded components, and toughening agents. ${ }^{1-5}$ However, high molding temperatures and poor solubility in organic solvents make processability low. It is necessary to improve processability, in particular, the solubility. However, improvement of solubility is accompanied by lowering high thermal stability. One method for the improvement of solubility without lowering thermal stability is the introduction of rigid and zigzag structures or bulky units to the main chain. ${ }^{6-19}$ We previously reported that the introduction of the rigid and zigzag structures, such as 5,6-quinoxalinediyl unit, ${ }^{20,21}$ and $4,4^{\prime \prime}$-o-terphenyldiyl unit, ${ }^{22,23}$ into polymer backbone affords high thermal stability and good solubility in many organic solvents to aromatic polyarylates and poly(ether ether ketone)s. We reported that aromatic polyamides ${ }^{24}$ and polyimides ${ }^{25}$ having rigid, bulky, and zigzag 9,10-dihydro-9,10-obenzenoanthracene-1,5-diyl unit (2,7-triptycenediyl unit) in the main chain possess high thermal stability as well as good solubility. In this article, novel polyarylates 1 and poly(ether ether ketone)s 2 containing 2,7-triptycenediyl unit in the main chain were synthesized from 9,10-dihydro-9,10-o-benzenoanthracene-1,5-diol (2,7-triptycenediol; TRIDO) as a monomer, and their properties were investigated. As to polyesters and poly(ether ether ketone)s containing the triptycene structure, polyesters having the 9,10-o-benzenoanthracene-9,10-diyl (9,10-triptycenediyl) unit reported by Klanderman ${ }^{26}$ and Hoffmeister, ${ }^{27}$ polyarylates having the 9,10 -dihydro-

\footnotetext{
$\dagger$ To whom correspondence should be addressed
}

9,10-o-benzenoanthracene-1,4-diyl(2,5-triptycenediyl) unit reported by Mikitaev et al., ${ }^{28,29}$ and poly(ether ether ketone)s having the 2,5-triptycenediyl unit reported by Wilharm $^{30}$ are known. However, the 2,7-triptycenediyl structure is more unsymmetrical and zigzag than the triptycene structures already reported.

\section{RESULTS AND DISCUSSION}

\section{TRIDO Synthesis}

2,7-Triptycenediol (TRIDO) was reported by Kuritani et al. $^{31}$ However, the method for preparation needs eleven steps from 1,5-dichloroanthraquinone as starting material, which is not suitable for the monomer synthesis of engineering plastics. Therefore, we investigated an other route of TRIDO synthesis. Disodium anthraquinone-1,5-disulfonate (3) was reduced using zinc reported by Lampe ${ }^{32}$ followed by alkali fusion and acetylation to give 1,5-diacetoxyanthracene (6). Benzyne-addition to 6 yielded 2,7-diacetoxytriptycene (7), followed by hydrolysis to afford TRIDO, as shown in Scheme 1. The low yield of the benzyne-addition may be due to two electron-donating acetoxyl groups. Purification of TRIDO by recrystallization failed, since TRIDO was unstable and insoluble in common organic solvents. Therefore, 7 was purified and identified, and hydrolyzed just before polymerization. The literature melting point of TRIDO was reported by Kuritani et al. as $280^{\circ} \mathrm{C},{ }^{31}$ but, we did not observe a melting point of the hydrolyzate below $300^{\circ} \mathrm{C}$. Therefore, thermogravimetry-differential thermal analysis (TG-DTA) measurement of the hydrolyzate was conducted. The DTA thermogram showed an endothermic peak at $361^{\circ} \mathrm{C}$, and the TG curve showed weight decrease at $277-380^{\circ} \mathrm{C}$, attributed to sublimation. The hydrolyzate was identified as 
TRIDO by IR spectroscopy and elemental analysis.

\section{Polyarylates 1}

Polyarylates 1a and $\mathbf{1 b}$ were derived from TRIDO and aromatic dicarbonyl dichlorides, such as isophthaloyl dichloride (8a), and terephthaloyl dichloride $(\mathbf{8 b})$, by interfacial polycondensation in an organic solvent-aqueous alkaline solution system using benzyltriethylammonium chloride (BTEAC) as a phase transfer catalyst, ${ }^{33}$ as shown in Scheme 2. The products were identified as polyesters 1 by elemental analysis and IR spectroscopy. The results are summarized in Table I. When the amounts of dichloromethane as an organic solvent were investigated (runs $1-4$ ), the polymerization of 1a using $5.5 \mathrm{ml}$ of dichloromethane (run 3) afforded a polyester having the highest inherent viscosity. The value was $0.29 \mathrm{dlg}^{-1}$ and yield was $84 \%$. In the synthesis of $\mathbf{1 b}$ (runs $6-8$ ), the proper amount of dichlo-<smiles>O=C1c2cccc([N+](=O)[O-])c2C(=O)c2cccc(OS(=O)(=O)[O-])c21</smiles>

3<smiles>[123I]</smiles><smiles>NS(=O)(=O)c1cccc2cc3c([N+](=O)[O-])cccc3cc12</smiles>

4 1) $\mathrm{KOH}$<smiles>CC([O-])(O)O[W]=O</smiles><smiles>CC(=O)Oc1cccc2cc3cccc(OC(C)=O)c3cc12</smiles>

6
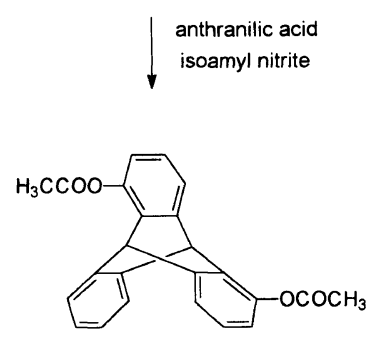

7

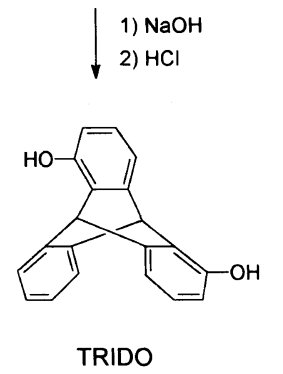

TRIDO
Scheme 2.

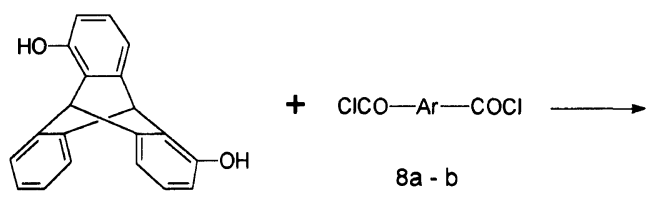

TRIDO romethane was $3.5 \mathrm{ml}$ (run 6). The inherent viscosity of the polyester obtained in run 6 was $0.51 \mathrm{dlg}^{-1}$, and yield was $84 \%$. When the organic solvent was changed from dichloromethane to chloroform in the polymerization of 1a, the inherent viscosity and yield were lowered (run 5).

As thermal properties, the temperatures at $5 \%$ weight loss $\left(\mathrm{T}_{\mathrm{d}} \mathrm{s}\right)$ and residual weights at $600^{\circ} \mathrm{C}$ and at $800^{\circ} \mathrm{C}$ were determined by TG in a nitrogen atmosphere. Glass transition temperatures $\left(T_{\mathrm{g}} \mathrm{s}\right)$ were determined by differential scanning calorimetry (DSC). The thermal properties of 1 are shown in Table II. $T_{\mathrm{d}}$ of $1 \mathrm{a}$ was $499^{\circ} \mathrm{C}$, and that of $1 \mathrm{~b}, 488^{\circ} \mathrm{C}$. These values were high. Residual weights at $600^{\circ} \mathrm{C}$ were above $58 \%$. $T_{\mathrm{g}}$ of $1 \mathrm{a}$ was $243^{\circ} \mathrm{C}$, and that of $1 \mathbf{b}$ was $249^{\circ} \mathrm{C}$. On each DSC curve, melting behavior was not observed. The introduction of the 2,7-triptycenediyl unit maintained the high thermal stability of polyarylates, which was attributed to the rigidity of the polymer backbone.

The solubility of polyarylates $\mathbf{1}$ in several organic solvents at $2.0 \%(\mathrm{w} / \mathrm{v})$ was examined, and the results are shown in Table III. 1a had high solubility, and was soluble in chloroform, tetrahydrofuran (THF), pyridine, $m$-cresol, $N, N$-dimethylacetamide (DMAc), and 1 methyl-2-pyrrolidone (NMP) at room temperature. 1b indicated improved solubility, and was soluble in NMP at $60^{\circ} \mathrm{C}$. But, the solubility of $1 \mathbf{b}$ was much lower than that of 1a, due to the more symmetrical 1,4-phenylene unit. Thus, introduction of 2,7-triptycenediyl structure improved the solubility of polyarylates without sacri-

Table I. Results of preparation of polyarylates $\mathbf{1}^{\mathrm{a}}$

\begin{tabular}{|c|c|c|c|c|c|}
\hline \multirow{2}{*}{ Run } & \multirow{2}{*}{ Polyarylate } & \multicolumn{2}{|l|}{ Organic solvent } & \multirow{2}{*}{$\frac{\text { Yield }}{\%}$} & \multirow{2}{*}{$\frac{\eta_{\mathrm{inh}}^{\mathrm{b}}}{\mathrm{dl} \mathrm{g}^{-1}}$} \\
\hline & & $\mathrm{ml}$ & & & \\
\hline 1 & 1a & dichloromethane & 3.5 & 16 & $-^{c}$ \\
\hline 2 & 1a & dichloromethane & 4.5 & 32 & 0.14 \\
\hline 3 & $\mathbf{1 a}$ & dichloromethane & 5.5 & 84 & 0.29 \\
\hline 4 & $1 \mathbf{a}$ & dichloromethane & 6.5 & 94 & 0.26 \\
\hline 5 & 1a & chloroform & 5.5 & 41 & 0.13 \\
\hline 6 & 1b & dichloromethane & 3.5 & 84 & 0.51 \\
\hline 7 & 1b & dichloromethane & 4.5 & 80 & 0.34 \\
\hline 8 & $\mathbf{1 b}$ & dichloromethane & 5.5 & 83 & 0.32 \\
\hline
\end{tabular}

${ }^{\text {a }}$ Polymerization was carried out with $1.25 \mathrm{mmol}$ of each monomer and $7.5 \mathrm{mg}$ benzyltriethylammonium chloride and $2.6 \mathrm{ml} 1 \mathrm{M}$ aqueous sodium hydroxide at room temperature for $40 \mathrm{~min}$. ${ }^{\mathrm{b}}$ Inherent viscosity, measured in NMP $\left(0.50 \mathrm{~g} \mathrm{dl}^{-1}\right)$ at $30^{\circ} \mathrm{C}$. ${ }^{\mathrm{c}}$ Inherent viscosity could not be measured because the yield was very low.

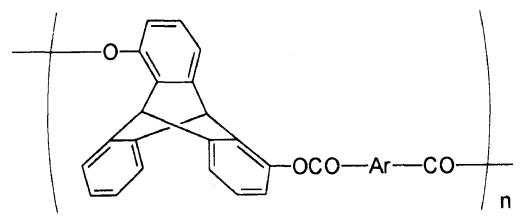

polyarylates $1 a-b$
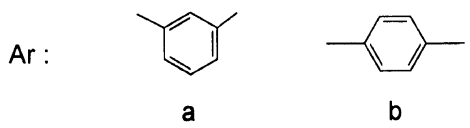

Scheme 1. 
ficing high thermal stability. X-Ray diffraction showed that $\mathbf{1 a}$ and $\mathbf{1 b}$ were amorphous. In many cases, polyarylates indicate crystalline features. But, the introduction of rigid, bulky, and zigzag 2,7-triptycenediyl structure led to an amorphous nature. It is considered that the amorphous nature of polyarylates 1 contributes to improved solubility.

\section{Poly(ether ether ketone)s 2}

Poly(ether ether ketone)s $\mathbf{2 c}$ and $\mathbf{2 d}$ were prepared by the nucleophilic displacement reaction ${ }^{14,15}$ of TRIDO with activated dihalides, such as 4,4'-difluorobenzophenone (9c) and 1,4-bis(4-fluorobenzoyl)benzene (9d), using potassium carbonate and toluene, as shown in Scheme 3. The results are summarized in Table IV. The effect of monomer concentration was examined in the polymerization of $2 \mathrm{c}$ using DMAc as an aprotic polar solvent (runs

Table II. Thermal properties of polyarylates 1 and poly(ether ether ketone)s 2

\begin{tabular}{|c|c|c|c|c|c|c|}
\hline \multirow{2}{*}{ Run $^{a}$} & \multirow{2}{*}{ Polymer } & \multirow{2}{*}{$\frac{T_{\mathrm{g}}^{\mathrm{b}}}{{ }^{\circ} \mathrm{C}}$} & \multirow{2}{*}{$\frac{T_{\mathrm{m}}^{\mathrm{c}}}{{ }^{\circ} \mathrm{C}}$} & \multirow{2}{*}{$\frac{T_{\mathrm{d}}^{\mathrm{d}}}{{ }^{\circ} \mathrm{C}}$} & \multicolumn{2}{|c|}{ Residual weight $/ \%^{\mathrm{e}}$} \\
\hline & & & & & at $600^{\circ} \mathrm{C}$ & at $800^{\circ} \mathrm{C}$ \\
\hline 3 & $1 \mathbf{a}$ & 243 & $-^{f}$ & 499 & 68 & 49 \\
\hline 6 & 1b & 249 & $-^{f}$ & 488 & 58 & 50 \\
\hline 10 & $2 c$ & 235 & $-^{f}$ & 568 & 82 & 72 \\
\hline 14 & 2d & 228 & 301 & 544 & 83 & 75 \\
\hline
\end{tabular}

a Sample run numbers appear in Tables I and IV. ${ }^{\mathrm{b}}$ Glass transition temperature, measured by differential scanning calorimetry (DSC). ${ }^{c}$ Melting point, measured by DSC. ${ }^{\mathrm{d}}$ Temperature at $5 \%$ weight loss in a nitrogen atmosphere, determined by thermogravimetry (TG). ${ }^{\mathrm{e}}$ Determined by TG in a nitrogen atmosphere. ${ }^{\mathrm{f}}$ Not observed.

Table III. Solubilities of polyarylates 1 and poly(ether ether ketone)s $2^{\text {a }}$

\begin{tabular}{rlcccccc}
\hline Run $^{\text {b }}$ & Polymer & $\mathrm{CHCl}_{3}$ & THF & Py & $m$-Cre & DMAc & NMP \\
\hline 3 & 1a & + & + & + & + & + & + \\
6 & 1b & \pm & \pm & \pm & \pm & \pm & $(+)$ \\
10 & 2c & + & + & \pm & + & + & + \\
14 & 2d & \pm & \pm & \pm & $( \pm)$ & \pm & $( \pm)$
\end{tabular}

a Measured at $2.0 \%(\mathrm{w} / \mathrm{v})$. Data in parentheses were obtained during heating at $60^{\circ} \mathrm{C}$. THF, tetrahydrofuran; Py, pyridine; $m$-Cre, $m$-cresol; DMAc, $N, N$-dimethylacetamide; NMP, 1-methyl-2-pyrrolidone. +, soluble; \pm , partially soluble; - , insoluble. ' Sample run numbers appear in Tables I and IV.
9-11). The polymerization at monomer concentration of $0.50 \mathrm{moll}^{-1}$ was favorable (run 10). Inherent viscosity was $0.30 \mathrm{dl} \mathrm{g}^{-1}$, and yield was virtually quantitative. The use of DMAc as a solvent (run 10) gives better results of the polymerization than that of NMP (run 12). The polymerization of $\mathbf{2 d}$ was performed under the same conditions as for run 9 (run 13). The inherent viscosity was $0.31 \mathrm{dl} \mathrm{g}^{-1}$, and yield, $99 \%$.

The thermal properties of 2 are also tabulated in Table II. $T_{\mathrm{d}} \mathrm{s}$ of 2 were above $540^{\circ} \mathrm{C}$. Residual weights at $600^{\circ} \mathrm{C}$ were $c a .82 \%$, and even those at $800^{\circ} \mathrm{C}$ were $c a .72 \% .2$ had the high thermal stability. $T_{\mathrm{g}}$ of $2 \mathrm{c}$ was $235^{\circ} \mathrm{C}$, and that of $2 \mathbf{d}$ was $228^{\circ} \mathrm{C}$. The DSC curve of $2 \mathbf{d}$ showed a melting point at $301{ }^{\circ} \mathrm{C}$ while melting was not observed in that of 2c. X-Ray diffraction showed that $\mathbf{2 c}$ was amorphous, but $2 \mathbf{d}$ was semi-crystalline, interestingly, as shown in Figure 1. We previously reported that aromatic polyamides ${ }^{24}$ and polyimides ${ }^{25}$ containing 2,7-triptycenediyl structure are amorphous, and as mentioned above, polyarylates 1 are also amorphous. Among polymers containing rigid and zigzag 4,4"-o-terphenyldiyl structure, some polyarylates have semi-crystalline nature ${ }^{23}$ while the aromatic polyamides, polyimides and polyethers are all amorphous. ${ }^{22,36,37}$ The combination of rigid, bulky, and zigzag structures, such as 2,7triptycenediyl or the $4,4^{\prime \prime}-o$-terphenyldiyl unit, with a flexible ester or ether linkage in the main chain may be more favorable for crystal formation than a rigid amide linkage or imide structure.

The solubility of $\mathbf{2}$ is shown in Table III. $\mathbf{2} \mathbf{c}$ had good

Table IV. Results of preparation of poly(ether ether ketone)s $\mathbf{2}^{\mathrm{a}}$

\begin{tabular}{|c|c|c|c|c|c|}
\hline \multirow{2}{*}{ Run } & \multirow{2}{*}{ Polymer } & \multirow{2}{*}{ Solvent } & \multirow{2}{*}{$\frac{[\mathrm{M}]}{\mathrm{moll}^{-1}}$} & \multirow{2}{*}{$\frac{\text { Yield }}{\%}$} & \multirow{2}{*}{$\frac{\eta_{\text {inh }}{ }^{b}}{d l g^{-1}}$} \\
\hline & & & & & \\
\hline 9 & $2 c$ & DMAc & 0.33 & 99 & 0.19 \\
\hline 10 & $2 c$ & DMAc & 0.50 & 96 & 0.30 \\
\hline 11 & $2 c$ & DMAc & 0.66 & 97 & 0.13 \\
\hline 12 & $2 c$ & NMP & 0.50 & 95 & 0.11 \\
\hline 13 & 2d & DMAc & 0.33 & 99 & $0.31^{\mathrm{c}}$ \\
\hline 14 & $2 d$ & DMAc & 0.50 & 101 & $0.47^{\mathrm{c}}$ \\
\hline
\end{tabular}

${ }^{\text {a }}$ Polymerization was carried out with $1.00 \mathrm{mmol}$ of each monomer, $2.32 \mathrm{mmol}$ anhydrous potassium carbonate, $2 \mathrm{ml}$ toluene, and a solvent at $135^{\circ} \mathrm{C}$ for $4 \mathrm{~h}$, and then at $155^{\circ} \mathrm{C}$ for $15 \mathrm{~h}$. ${ }^{b}$ Inherent viscosity, measured in NMP $\left(0.50 \mathrm{~g} \mathrm{dl}^{-1}\right)$ at $30^{\circ} \mathrm{C}$. ${ }^{\mathrm{c}}$ Measured in conc. sulfuric acid $\left(0.50 \mathrm{~g} \mathrm{dl}^{-1}\right)$ at $30^{\circ} \mathrm{C}$.

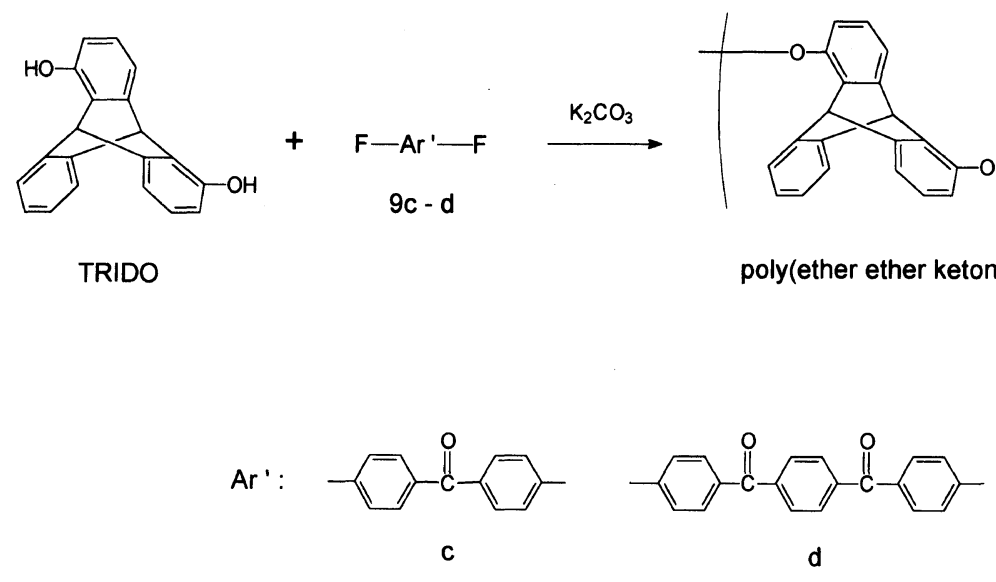

Scheme 3. 


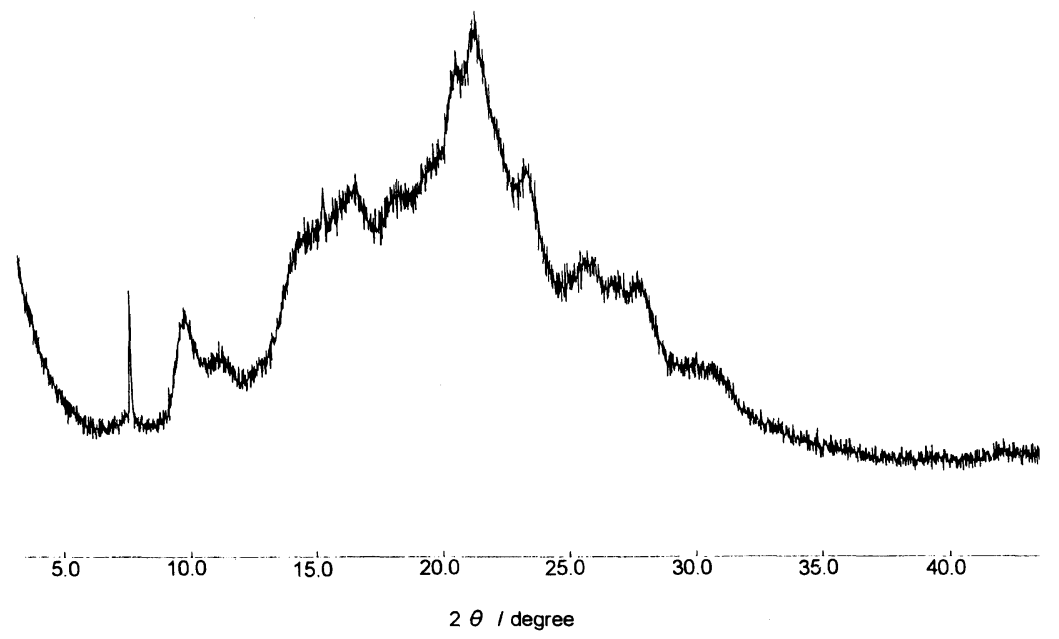

Figure 1. X-Ray diffraction pattern of $\mathbf{2 d}$.

solubility for poly(ether ether ketone), which was soluble in chloroform, THF, $m$-cresol, DMAc, and NMP at room temperature. Thus, $\mathbf{2} \mathbf{c}$ showed improved solubility as well as high thermal stability. However, 2d showed lower solubility. Although the structure of $\mathbf{2 d}$ is different from that of $\mathbf{2 c}$ somewhat, the solubility of $\mathbf{2 d}$ was much lower. The crystallinity of polymers influences solubility. The lower solubility of $\mathbf{2 d}$ is attributed to the semi-crystalline nature.

\section{CONCLUSION}

It is concluded that the introduction of 2,7-triptycenediyl moiety to the main chain of polyarylates improves solubility, while maintaining high thermal stability. Introduction of the 2,7-triptycenediyl unit to the backbone of poly(ether ether ketone)s also has effect on improvement of solubility without lowering high thermal stability. However, 2d shows lower solubility and melting behavior due to the semi-crystalline nature.

\section{EXPERIMENTAL}

\section{1,5-Diacetoxyanthracene 6}

Disodium 1,5-anthraquinonedisulfonate (3) (Tokyo Chemical Industry Co., Ltd.) was reduced using zinc dust according to the method reported by Lampe, ${ }^{32}$ affording disodium 1,5-anthracenedisulfonate (4).

$96.4 \mathrm{~g}$ of potassium hydroxide $(0.58 \mathrm{~mol})$ were added in the vessel equipped with a thermometer, and heated to $320^{\circ} \mathrm{C}$ until fusing. $30.4 \mathrm{~g}$ of $4(79 \mathrm{mmol})$ were added gradually with stirring, and the mixture was heated at $340^{\circ} \mathrm{C}$ for $3 \mathrm{~h}$, and then at $350^{\circ} \mathrm{C}$ for $3 \mathrm{~h}$. After cooling, the reaction mixture was dissolved in $800 \mathrm{ml}$ of water, and $500 \mathrm{ml}$ of $4 \mathrm{M} \mathrm{HCl}$ were added to form a green precipitate. The product was washed twice with water, and dried under reduced pressure. $22.2 \mathrm{~g}$ of crude 5 were obtained.

In a flask equipped with a reflux condenser were added $22.2 \mathrm{~g}$ of crude 5 and $350 \mathrm{ml}$ of acetic anhydride. The mixture was stirred at room temperature for $1 \mathrm{~h}$. A drop of conc. sulfuric acid was added, and the reaction mixture was stirred at room temperature for $30 \mathrm{~min}$, and at $110^{\circ} \mathrm{C}$ for $3 \mathrm{~h}$. It was poured into ice-water, and the product was collected with a glass filter, washed twice with water, and dried under reduced pressure. The product was recrystallized from ethyl acetate to give brown needles. Yield from $471 \%$. mp $202.8-204.2^{\circ} \mathrm{C}$ (lit., ${ }^{32} 198^{\circ} \mathrm{C}$ ). IR (KBr, disk) $1760 \mathrm{~cm}^{-1}(\mathrm{C}=\mathrm{O}), 1200,1084 \mathrm{~cm}^{-1}$ (C-O). ${ }^{1} \mathrm{H}$ NMR $\left(60 \mathrm{MHz}, \mathrm{CDCl}_{3}\right): \delta=2.33(\mathrm{~s} ; 6 \mathrm{H}$, $\left.-\mathrm{OCOCH}_{3}\right), 7.20(\mathrm{~m} ; 4 \mathrm{H}, \mathrm{Ar}-\mathrm{H}), 7.70(\mathrm{~d} ; 2 \mathrm{H}, \mathrm{Ar}-\mathrm{H})$, 8.25 (s; $2 \mathrm{H}$, Ar-H). Anal. Calcd for $\mathrm{C}_{18} \mathrm{H}_{14} \mathrm{O}_{4}(294.3)$ : C, $73.46 \%$; H, $4.79 \%$. Found: C, $73.68 \%$; H, $4.70 \%$.

\section{2,7-Diacetoxytriptycene 7}

In a flask equipped with a reflux condenser and dropping funnel were added $12.5 \mathrm{~g}$ of $6(42.5 \mathrm{mmol})$ and $120 \mathrm{ml}$ of dichloromethane. After all the solids were dissolved, $8.8 \mathrm{ml}$ of isopentyl nitrite $(66 \mathrm{mmol})$ were added. A solution of $16.8 \mathrm{~g}$ of anthranilic acid in $45 \mathrm{ml}$ of tetrahydrofuran was added gradually in $3.5 \mathrm{~h}$ while refluxing. The mixture was refluxed for $30 \mathrm{~min}$. After cooling, the solvents were evaporated off. The product was dissolved in $80 \mathrm{ml}$ of xylene, $4.2 \mathrm{~g}$ of maleic anhydride $(43 \mathrm{mmol})$ were added. The mixture was refluxed for $20 \mathrm{~min} .400 \mathrm{ml}$ of water and $190 \mathrm{ml}$ of dichloromethane were added, and the organic layer was washed twice with $15 \mathrm{wt} \%$ of aqueous potassium hydroxide, once with saturated brine, and twice with water. It was dried with anhydrous sodium sulfate, and the solvents were removed by a distillation. Crude yield $55 \%$. The product was recrystallized from benzene to afford yellow needles. Yield $26 \%$. mp $225.0-226.3^{\circ} \mathrm{C}$ (lit., ${ }^{31} 209.8-213.7^{\circ} \mathrm{C}$ ). IR $\left(\mathrm{KBr}\right.$, disk) $1758 \mathrm{~cm}^{-1}(\mathrm{C}=\mathrm{O}), 1202,1100 \mathrm{~cm}^{-1}$ (C-O). ${ }^{1} \mathrm{H}$ NMR $\left(60 \mathrm{MHz}, \mathrm{CDCl}_{3}\right): \delta=2.40(\mathrm{~s} ; 6 \mathrm{H}$, $\left.-\mathrm{OCOC}_{3}\right), 5.35\left(\mathrm{~s} ; 2 \mathrm{H}, \mathrm{C}_{9,10}-\mathrm{H}\right), 6.50-7.30(\mathrm{~m} ; 10 \mathrm{H}$, Ar-H). Anal. Calcd for $\mathrm{C}_{24} \mathrm{H}_{18} \mathrm{O}_{4}$ (370.4): C, 77.82\%; $\mathrm{H}, 4.90 \%$. Found: C, $77.89 \%$; H, $4.84 \%$.

\section{2,7-Triptycenediol TRIDO}

$4.02 \mathrm{~g}$ of $7(10.9 \mathrm{mmol})$ were dissolved in $35 \mathrm{ml}$ of ethanol, to which aqueous sodium hydroxide $(2.8 \mathrm{~g} / 7 \mathrm{ml})$ was added. The mixture was refluxed for $30 \mathrm{~min}$, and $140 \mathrm{ml}$ of water were added. $20 \mathrm{ml}$ of hydrochloric acid were added to the precipitate. The product was washed twice with water, dried under reduced pressure to give white powder. Yield $96 \%$. mp $361^{\circ} \mathrm{C}$ (DTA, sublimed at $277-380^{\circ} \mathrm{C}$ ) (lit., ${ }^{31} 280^{\circ} \mathrm{C}$ ). IR ( $\mathrm{KBr}$, disk) 3500 
$3000 \mathrm{~cm}^{-1}(\mathrm{O}-\mathrm{H})$. Anal. Calcd for $\mathrm{C}_{20} \mathrm{H}_{14} \mathrm{O}_{2}$ (286.3): $\mathrm{C}$, $83.90 \%$; H, $4.93 \%$. Found: C, $83.60 \%$; H, 5.03\%.

\section{Other Monomers}

Isophthaloyl dichloride (8a), terephthaloyl dichloride (8b), and 4,4'-difluorobenzophenone (9c) were commercially available and used after recrystallization $(\mathbf{8 a}$, from dry hexane; 8b, from dry ligroin; 9c, from ethanol). 1,4-Bis(4-fluorobenzoyl)benzene (9d) was prepared as reported by Hergenrother, ${ }^{5)}$ and used after recrystallization from dry toluene.

\section{Polycondensations of Polyarylates 1}

A typical procedure is as follows (run 3): In a homogenizer equipped with a mechanical stirrer, TRIDO $(0.3585 \mathrm{~g}, 1.25 \mathrm{mmol})$ was placed, and dissolved in $2.6 \mathrm{ml}$ $1 \mathrm{M}$ aqueous $\mathrm{NaOH}$ solution with stirring, and $7.5 \mathrm{mg}$ of BTEAC was added. A solution of $0.2532 \mathrm{~g}(1.25 \mathrm{mmol})$ of $\mathbf{8 a}$ in $5.5 \mathrm{ml}$ dichloromethane was added all at once with vigorous stirring. The reaction mixture was stirred for $40 \mathrm{~min}$ at room temperature, and poured into hot water for precipitation. The products were collected by filtration with a glass filter, washed with hot methanol, and dried under reduced pressure at $60^{\circ} \mathrm{C}$. Yield $84 \%$. $\eta_{\text {inh }}=0.29 \mathrm{dl} \mathrm{g}^{-1}\left(0.5 \mathrm{~g} \mathrm{dl}^{-1}\right.$ in NMP at $\left.30^{\circ} \mathrm{C}\right)$. IR $(\mathrm{KBr}$, disk) $1744 \mathrm{~cm}^{-1}(\mathrm{C}=\mathrm{O}), 1214 \mathrm{~cm}^{-1}(\mathrm{C}-\mathrm{O})$. Anal. Calcd for $\left(\mathrm{C}_{28} \mathrm{H}_{16} \mathrm{O}_{4}\right)_{n}(416.4)_{n}: \mathrm{C}, 80.76 \% ; \mathrm{H}, 3.87 \%$. Found: C, $78.02 \%$; H, $3.83 \%$.

Other polyarylates were synthesized by a similar procedure.

\section{Polycondensations of Poly(ether ether ketone)s $\mathbf{2}$}

A typical procedure is as follows (run 10): In a 10-ml reaction tube equipped with a Dean-Stark trap, a reflux condenser, a mechanical stirrer, and a nitrogen gas inlet having a calcium chloride tube were placed TRIDO $(0.2863 \mathrm{~g}, 1.00 \mathrm{mmol})$, dihalide $9 \mathrm{c}(0.2183 \mathrm{~g}, 1.00 \mathrm{mmol})$, and $2.0 \mathrm{ml}$ of DMAc. The mixture was stirred to dissolve the solids, and powdered anhydrous potassium carbonate $(0.320 \mathrm{~g}, 2.32 \mathrm{mmol})$ and $2.0 \mathrm{ml}$ of dry toluene were added. The mixture was heated to $135^{\circ} \mathrm{C}$ for $4 \mathrm{~h}$ under a Dean-Stark trap to remove caused water by azeotropy, and $155^{\circ} \mathrm{C}$ for $15 \mathrm{~h}$. The reaction mixture was diluted with DMAc, and poured into acetic acid / water mixture (acetic acid: $\mathrm{H}_{2} \mathrm{O}=1: 20$ in volume). The formed precipitate was collected with a glass filter, washed with hot water and with hot methanol, and dried under reduced pressure at $60^{\circ} \mathrm{C}$. Yield $96 \% . \eta_{\text {inh }}=0.30 \mathrm{dl} \mathrm{g}^{-1}$ $\left(0.5 \mathrm{~g} \mathrm{dl}^{-1}\right.$ in NMP at $\left.30^{\circ} \mathrm{C}\right)$. IR ( $\mathrm{KBr}$, disk) $1238 \mathrm{~cm}^{-1}$ (C-O). Anal. Calcd for $\left(\mathrm{C}_{33} \mathrm{H}_{20} \mathrm{O}_{3}\right)_{n}(464.5)_{n}$ : C, $85.33 \%$; $\mathrm{H}, 4.34 \%$. Found: C, $83.04 \%$; H, $4.30 \%$.

Other poly(ether ether ketone)s were synthesized by a similar procedure.

\section{Measurements}

$T_{\mathrm{g}} \mathrm{s}$ and a $T_{\mathrm{m}}$ were measured by DSC (MAC Science DSC 3100), and determined by second scannings. $T_{\mathrm{d}} \mathrm{s}$ and residual weights were determined by TG (MAC Science TG-DTA 2000). Measurements of DSC and TG-DTA were carried out under the following conditions: heating rate, $10 \mathrm{~K} \mathrm{~min}^{-1}$; in a nitrogen atmosphere. IR spectra were recorded on a Hitachi 270-30 spectrophotometer. ${ }^{1} \mathrm{H}$ NMR spectra were obtained with a $60 \mathrm{MHz}$ Hitachi R24B NMR spectrometer. Wide angle X-ray diffraction patterns of 1 were obtained for specimens on a Rigaku RAD-B X-ray diffraction apparatus with $\mathrm{Cu}-K_{\alpha}$ radiation $(35 \mathrm{kV}, 20 \mathrm{~mA})$ using virgin samples. Those of $\mathbf{2}$ were measured on a MAC-Science MXP-18 X-ray diffraction apparatus with $\mathrm{Cu}-K_{\alpha}$ radiation $(40 \mathrm{kV}, 300 \mathrm{~mA})$ using virgin samples.

Acknowledgments. The authors thank Ms. Hiroko Seki, Chemical Analysis Center, Chiba University, for performing the elemental analysis.

\section{REFERENCES}

1. P. E. Cassidy, "Thermally Stable Polymers, Synthesis and Properties," Dekker, New York, N. Y., 1980.

2. R. B. Seymour and G. S. Krishenbaum, "High Performance Polymers: Their Origin and Development," Elsevier, New York, N.Y., 1986.

3. R. N. Johnson, A. G. Farnham, R. A. Clendinning, W. F. Hale, and C. N. Marrian, J. Polym. Sci., Part A-1, 5, 2375 (1967).

4. J. B. Rose and P. A. Staniland, US Patent, 4320224(1982), [Chem. Abstr., 96, 200397d (1982)].

5. P. M. Hergenrother, B. J. Jensen, and S. J. Havens, Polymer, 29, 358 (1988).

6. Y. Imai and S. Tassavori, J. Polym. Sci., Polym. Chem. Ed., 22, 1319 (1984).

7. M. Kakimoto, Y. S. Negi, and Y. Imai, J. Polym. Sci., Polym. Chem. Ed., 24, 1511 (1986).

8. M. Yoneyama, K. D. A. Kuruppu, M. Kakimoto, and Y. Imai, J. Polym. Sci., Part A, Polym. Chem., 27, 979 (1989).

9. C.-P. Yang, Y. Oishi, M. Kakimoto, and Y. Imai, J. Polym. Sci., Part A, Polym. Chem., 28, 1353 (1990).

10. H.-J. Jeong, M. Kakimoto, and Y. Imai, J. Polym. Sci., Part A, Polym. Chem., 29, 1293 (1991).

11. G.-S. Liou, M. Kakimoto, and Y. Imai, J. Polym. Sci., Part A, Polym. Chem., 30, 2195 (1992).

12. F. Keitoku, M. Kakimoto, and Y. Imai, J. Polym. Sci., Part A, Polym. Chem., 32, 317 (1994).

13. G.-S. Liou, M. Kakimoto, and Y. Imai, J. Polym. Sci., Part A, Polym. Chem., 32, 591 (1994).

14. S. Watanabe, A. Kobayashi, M. Kakimoto, and Y. Imai, J. Polym. Sci., Part A, Polym. Chem., 32, 909 (1994).

15. H.-J. Jeong, M. Kakimoto, and Y. Imai, J. Polym. Sci., Part A, Polym. Chem., 32, 1057 (1994).

16. Z. Y. Wang and A. S. Hay, J. Polym. Sci., Part A, Polym. Chem., 29, 1045 (1991).

17. Y. Saegusa, A. Kojima, and S. Nakamura, Makromol. Chem., 194, 777 (1993)

18. F. Wang and J. Roovers, J. Polym. Sci., Part A, Polym. Chem., 32, 2413 (1994)

19. Y. Taguchi, H. Uyama, and S. Kobayashi, J. Polym. Sci., Part A, Polym. Chem., 34, 2413 (1996).

20. F. Akutsu, S. Yoshioka, Y. Suzuki, K. Naruchi, M. Miura, and K. Nagakubo, Makromol. Chem., Rapid Commun., 8, 113 (1987).

21. F. Akutsu, H. Nemoto, K. Naruchi, M. Miura, and K. Nagakubo, Makromol. Chem., Rapid Commun., 10, 237 (1989).

22. F. Akutsu, K. Takahashi, Y. Kasashima, M. Inoki, and K. Naruchi, Macromol. Chem., Rapid Commun., 16, 495 (1995).

23. F. Akutsu, M. Inoki, K. Takahashi, T. Yonemura, Y. Kasashima, and K. Naruchi, Polym. J., 28, 1107 (1996).

24. Y. Kasashima, T. Kaneda, G. Saito, F. Akutsu, K. Naruchi, and M. Miura, Macromol. Chem. Phys., 195, 2693 (1994).

25. F. Akutsu, G. Saito, M. Miyamoto, Y. Kasashima, M. Inoki, and K. Naruchi, Macromol. Chem. Phys., 197, 2239 (1996)

26. B. H. Klanderman and J. W. H. Faber, J. Polym. Sci., A-1, 6, 2955 (1968)

27. E. Hoffmeister, J. E. Kropp, T. L. Mcdowell, R. H. Michel, and W. L. Rippie, J. Polym. Sci., Part A-1, 7, 55 (1969).

28. A. K. Mikitaev, V. V. Korshak, Kh. Kh. Gurdaliev, V. N. Pryadko, V. N. Belousov, and K. V. Kalmykov, Dokl. Akad. Nauk SSSR, 269, 127 (1983) [Chem. Abstr., 99, 6391u (1983)].

29. G. V. Kozlov, E. R. Kekharaseva, V. N. Shogenov, A. S. 
Beriketov, A. M. Kharaev, and A. K. Mikitaev, Vysokomol. Soedin. Ser. B, 28, 3 (1986) [Chem. Abstr., 104, 208020e (1986)].

30. P. Wilharm, Ger. Patent, DE 4121138 (1993) [Chem. Abstr., 119, 161063p (1993)].

31. M. Kuritani, Y. Sakata, F. Ogura, and M. Nakagawa, Bull. Chem. Soc. Jpn., 46, 605 (1973).

32. B. Lampe, Chem. Ber., 42, 1413 (1909).

33. P. W. Morgan, "Condensation Polymers by Interfacial and Solution Methods," Interscience, New York, N.Y., 1965.
34. D. K. Mohanty, J. L. Hedrick, K. Gobetz, B. C. Johnson, I. Yilgor, R. Yang, and J. E. McGrath, Polym. Prepr. Am. Chem. Soc., Div. Polym. Chem., 23, 1827 (1984).

35. R. Viswanathan, B. C. Johnson, and J. E. MaGrath, Polymer, 25, 1827 (1984).

36. Y. Kasashima, K. Yamamoto, N. Ando, F. Akutsu, K. Naruchi, and M. Miura, Polym. J., 26, 1298(1994).

37. Y. Kasashima, H. Kumada, K. Yamamoto, F. Akutsu, K Naruchi, and M. Miura, Polymer, 36, 645 (1995). 